\title{
Seismic Fragility Analysis of Mid-Story Isolation Buildings
}

\author{
Xiao Song ${ }^{1,2, a}$ and Songtao Xue $\mathrm{X}^{1,3, \mathrm{~b},{ }^{*}}$ \\ ${ }^{1}$ Department of Architecture, Tohoku Institute of Technology, Sendai, Japan \\ ${ }^{2}$ Department of Civil Engineering, Henan University, Kaifeng 475001, P.R. China \\ ${ }^{3}$ Department of Disaster Mitigation for Structures, Tongji University, Shanghai, P.R. China \\ a songxiao@henu.edu.cn, ${ }^{b}$ xuest@tohtech.ac.jp
}

\begin{abstract}
Keywords: Mid-Story Isolation Buildings, Fragility Curves, Seismic Risk Assessment, Incremental Dynamic Analysis
\end{abstract}

\begin{abstract}
Seismic fragility analysis is essential for seismic risk assessment of structures. This study focuses on the damage probability assessment of the mid-story isolation buildings with different locations of the isolation system. To this end, the performance-based fragility analysis method of the mid-story isolation system is proposed, adopting the maximum story drifts of structures above and below the isolation layer and displacement of the isolation layer as performance indicators. Then, the entire process of the mid-story isolation system, from the initial elastic state to the elastic-plastic state, then to the limit state, is simulated on the basis of the incremental dynamic analysis method. Seismic fragility curves are obtained for mid-story isolation buildings with different locations of the isolation layer, each with fragility curves for near-field and far-field ground motions, respectively. The results indicate that the seismic fragility probability subjected to the near-field ground motions is much greater than those subjected to the far-field ground motions. In addition, with the increase of the location of the isolation layer, the dominant components for the failure of mid-story isolated structures change from superstructure and isolation system to substructure and isolation system.
\end{abstract}

\section{Introduction}

Seismic isolation technology has proven to be one of the most effective strategies for seismic design of structures. The mid-story isolation technology, in which the isolation layer is installed at the inter-story rather than at the base of the building, is gaining popularity recently and can prevent the pounding between the isolation layer and moat walls. It is suitable for the retrofit of existing buildings and other buildings that are not suitable for base isolation. Previous researches demonstrate the effectiveness of the mid-story isolation system for vibration reduction performance under fortification earthquakes [1,2]. However, due to the uncertainty of earthquakes, the intensity of an actual earthquake can be considerably greater than that specified in the seismic code. In addition, near-field earthquakes, characterized by long-period and short-duration, can amplify the seismic responses of buildings and increase the damage probability of mid-story isolation buildings.

Earthquake damage investigations show that casualties are mainly caused by the collapse of building structures. At present, the most widely used approach for seismic performance evaluation is the incremental dynamic analysis [3,4]. Vamvatsikos et al. developed and applied the incremental dynamic analysis to predict collapse under the effect of scaled earthquake records [5]. Mansouri et al. conducted the seismic fragility analysis for 3- and 9-story base-isolated buildings [6]. It was found that the installation of the isolation layer decreased the amount of failure probability. On the other hand, seismic responses subjected to near-field earthquakes are different 
from those subjected to far-field earthquakes. Bhandari et al. evaluated the seismic performance of a 10-story base-isolated RC frame under the far- and near-field earthquakes [7]. The results indicated that even for the low PGA value, the near-field earthquakes cause a high probability of damage to the base-isolated structure.

The above literature focused on the performance assessment of base-isolated structures and non-isolated structures. The seismic performance of the mid-isolated system under severe earthquakes is rarely studied, and the failure patterns under severe earthquakes have not been fully understood. To this end, nonlinear dynamic response analysis of a 10-story RC frame, designed according to the seismic design code of buildings in China, is carried out with incremental dynamic analysis (IDA), considering the different locations of the isolation layer for the mid-story isolation buildings. Fragility curves for mid-story isolation structures, corresponding to four performance levels, are generated subjected to near-field and far-field records.

\section{Fragility analysis method}

The seismic fragility of the structures is the exceedance probability of certain damage state under the given intensity of earthquakes. For performance-based seismic design, failure means that the structure cannot meet a certain predetermined performance level. For this study, fragility analysis is performed based on IDA. The main analyzing steps are as follows: 1. Conduct a nonlinear dynamic analysis model for both base-fixed and mid-isolated structures. 2. Select seismic records that representing different site characteristics, select appropriate ground motion intensity measurements, and perform amplitude modulation for each ground motion. 3. Conduct the nonlinear time-history response analysis for under earthquake with a certain intensity, count the records of ground motions that exceed the certain performance level, the probability of exceeding under the intensity of ground motions can be obtained. 4. Scale the ground motions and repeat step 3 , then the damage measurements and the exceeding probability under different ground motion intensity can be obtained. 5. Adopt a certain probability model, the fragility curves can be developed corresponding to different earthquake intensity and performance levels of structures.

According to related studies[8,9], it is assumed that the fragility function can be approximated by the log-normal probability distribution function and the fragility function can be defined as follows:

$$
P\left(L S_{i} \mid I M=i m\right)=P\left(D M \geq d m_{i} \mid I M=i m\right)
$$

Where $L S$ is the limit state, and $P(\bullet)$ is the probability of exceeding the given performance level with the earthquake intensity $\mathrm{IM}=i m$, and $D M$ is the dynamic response of the structure. Consequently, the probability of exceeding the damage measure of the particular intensity can be expressed by Eq. (2)

$$
P(D M \mid I M=i m)=1-P\left(D M<d m_{i} \mid I M=i m\right)=1-\Phi\left[\frac{\ln d m_{i}-\mu_{\ln D M \mid \mathrm{IM}=i m}}{\sigma_{\ln D M \mid \mathrm{IM}=i m}}\right]
$$

Where $\mu$ is the logarithmic median value and $\sigma$ is the standard deviation of DM, and $\Phi(\cdot)$ is the standard normal cumulative distribution function. $\mu$ and $\sigma$ can be calculated from IDA. Then, the seismic fragility curves under near- and far-field ground motions corresponding to different performance levels can be obtained.

\section{Damage measures and damage states}

In order to assess the structural performance levels under different intensity ground motions, the inter-story drift of the structures, the deformation, and the stress of the isolation bearings are selected as the damage measures to perform the fragility analysis with different performance 
levels. According to the methodology defined in the Federal Emergency Management Agency [10] and the seismic design code of buildings in China, structural performance levels against earthquakes can be clarified into operational, immediate occupancy, life safety, and collapse prevention performance levels. Corresponding to the four performance levels, the damage states are defined as slight (DS1), moderate (DS2), extensive (DS3), and collapse (DS4), respectively. Table 1 shows the damage states thresholds for different damage measures.

Table 1. Damage states thresholds for different damage measures

\begin{tabular}{lcccc}
\hline & \multicolumn{4}{c}{ Damage states } \\
Damage measures & $\begin{array}{c}\text { Slight } \\
\text { (DS1) }\end{array}$ & $\begin{array}{c}\text { Moderate } \\
(\mathrm{DS} 2)\end{array}$ & $\begin{array}{c}\text { Extensive } \\
(\mathrm{DS} 3)\end{array}$ & $\begin{array}{c}\text { Collapse } \\
\text { (DS4) }\end{array}$ \\
\hline $\begin{array}{l}\text { Inter-story drift of } \\
\text { structures }\end{array}$ & $1 / 550$ & $1 / 275$ & $1 / 150$ & $1 / 50$ \\
$\begin{array}{l}\text { Displacement and stress of } \\
\text { isolation bearings }\end{array}$ & -- & -- & $0.6 D_{\max }$ & $1.0 D_{\max }$ \\
{$\left[\sigma \min , \sigma_{\max }\right]$} & {$\left[\sigma_{\min }, \sigma_{\max }\right]$} \\
\hline
\end{tabular}

Note: $D_{\max }$ is the maximum isolator design displacement, $\mathrm{D}_{\max }=\operatorname{Min}\left\{0.55 D, 3 T_{\mathrm{r}}\right\}$, where $D$ is the diameter of isolation bearing, $T_{\mathrm{r}}$ is the total thickness of the rubber layer, and $\sigma_{\min }, \sigma_{\max }$ are the thresholds of the stress of isolation bearing.

\section{Selection of earthquake records}

The selection of earthquake ground motion records is essential for IDA and fragility analysis. Two types of earthquake ground motions, recommended by FEMA P695[10], are selected, including 13 near-field and 13 far-field records. The elastic acceleration response spectra of selected earthquake records are shown in Fig. 1, and the basic information is tabulated in Tables 2-3.

Table 2. Basic information of selected ground motions (Far-Field records set)

\begin{tabular}{lllccll}
\hline No & \multicolumn{1}{c}{ Event } & \multicolumn{1}{c}{ Station } & Year & $M_{\mathrm{w}}$ & PGA(g) & Component \\
\hline 1 & San_Fernando & LA-Hollywood_Stor_FF & 1971 & 6.6 & 0.210 & PEL090 \\
2 & San_Fernando & LA-Hollywood_Stor_FF & 1971 & 6.6 & 0.174 & PEL180 \\
3 & Friuli-Italy-01 & Tolmezzo & 1976 & 6.5 & 0.315 & A-TMZ270 \\
4 & Imperial_Valley-06 & El_Centro_Array_\#11 & 1979 & 6.5 & 0.380 & H-E11230 \\
5 & Superstition_Hills-02 & Poe_Road_(temp) & 1987 & 6.5 & 0.446 & B-POE270 \\
6 & Cape_Mendocino & Rio_Del__Overpass-FF & 1992 & 7 & 0.385 & RIO270 \\
7 & Cape_Mendocino & Rio_Dell_Overpass-FF & 1992 & 7 & 0.549 & RIO360 \\
8 & Northridge-01 & Beverly_Hills-14145_Mulhol & 1994 & 6.7 & 0.416 & MUL009 \\
9 & Northridge-01 & Canyon_Country-W_Lost_Cany & 1994 & 6.7 & 0.410 & LOS000 \\
10 & Northridge-01 & Canyon_Country-W_Lost_Cany & 1994 & 6.7 & 0.482 & LOS270 \\
11 & Kobe-Japan & Nishi-Akashi & 1995 & 6.9 & 0.503 & NIS090 \\
12 & Chi-Chi-Taiwan & CHY101 & 1999 & 7.6 & 0.440 & CHY101-N \\
13 & Duzce-Turkey & Bolu & 1999 & 7.1 & 0.728 & BOL000 \\
\hline
\end{tabular}


Table 3. Basic information of selected ground motions (Near-Field records set)

\begin{tabular}{lllccll}
\hline No & \multicolumn{1}{c}{ Event } & \multicolumn{1}{c}{ Station Name } & Year & $M_{\mathrm{w}}$ & PGA(g) & Component \\
\hline 1 & Imperial_Valley-06 & El_Centro_Array_\#7 & 1979 & 6.5 & 0.3375 & H-E07140 \\
2 & Superstition_Hills-02 & Parachute_Test_Site & 1987 & 6.5 & 0.3772 & B-PTS315 \\
3 & Erzican-Turkey & Erzincan_-Ten & 1992 & 6.7 & 0.4955 & ERZ-EW \\
4 & Erzican-Turkey & Erzincan & 1992 & 6.7 & 0.5153 & ERZ-NS \\
5 & Cape_Mendocino & Petrolia & 1992 & 7 & 0.5896 & PET000 \\
6 & Cape_Mendocino & Petrolia & 1992 & 7 & 0.6624 & PET090 \\
7 & Northridge-01 & Rinaldi_Receiving_Sta & 1994 & 6.7 & 0.8252 & RRS228 \\
8 & Northridge-01 & Rinaldi_Receiving_Sta & 1994 & 6.7 & 0.4865 & RRS318 \\
9 & Northridge-01 & Sylmar-Olive_View_Med_FF & 1994 & 6.7 & 0.8433 & SYL360 \\
10 & Kocaeli-Turkey & Izmit & 1999 & 7.5 & 0.2195 & IZT090 \\
11 & Kocaeli-Turkey & Izmit & 1999 & 7.5 & 0.1521 & IZT180 \\
12 & Duzce-Turkey & Duzce & 1999 & 7.1 & 0.3481 & DZC180 \\
13 & Duzce-Turkey & Duzce & 1999 & 7.1 & 0.5353 & DZC270 \\
\hline
\end{tabular}

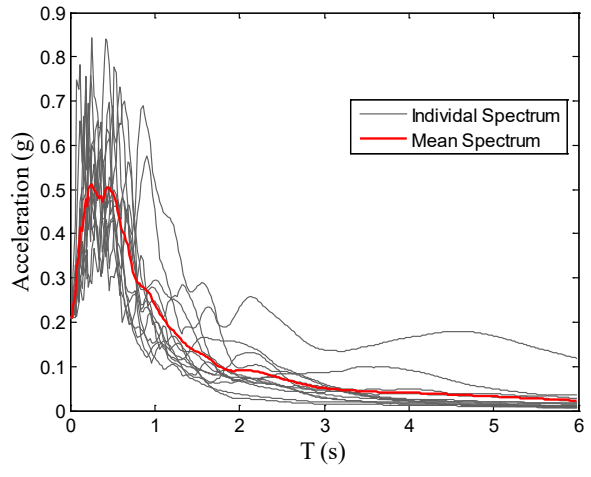

(a) Far-field set

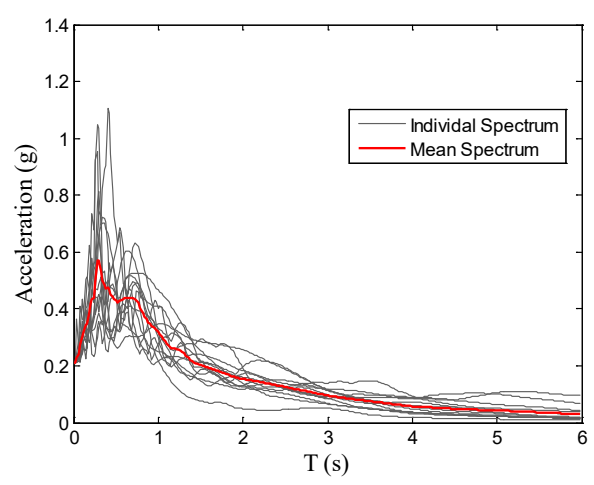

(b) Near-field set

Fig. 1. Acceleration response spectra of selected earthquake ground motion records

\section{Fragility analysis and risk assessment}

Structural models for the performance evaluation

In this study, a typical 10-story RC frame building designed according to the seismic design code of buildings in China is selected as the analytical model. The cross-section of columns is $700 \times 700 \mathrm{~mm}$, and the cross-section of beams is $250 \times 600 \mathrm{~mm}$ for all floors. The height is $3.9 \mathrm{~m}$ for the first floor and $3.6 \mathrm{~m}$ for other floors. The gravity loads are represented by dead loads $5.0 \mathrm{kN} / \mathrm{m}^{2}$, live loads $0.5 \mathrm{kN} / \mathrm{m}^{2}$, for the top floor; dead loads $4.5 \mathrm{kN} / \mathrm{m}^{2}$, live loads $2.0 \mathrm{kN} / \mathrm{m}^{2}$, for the typical floors. The frame at the center is chosen for numerical analysis.

To investigate the discrepancies of performance of mid-story isolation structures and non-isolated structure, as well as to reveal the influence of the position of the seismic isolation layer on the structural performance, three numerical models denoted as specimens Non-Iso, Iso-2, and Iso-5, are designed. The isolation layers of Iso-2 and Iso-5 are respectively installed on the top of the 2nd story and 5th story. For mid-isolated structures, stories below and above the isolation layers are denoted as superstructure (Sup) and substructure (Sub). Fig. 2 shows the details of the studied buildings. Bearings adopted for Iso-2 and Iso-5 are LRB 700 and LRB 600 respectively, designed according to the seismic design code in China. 


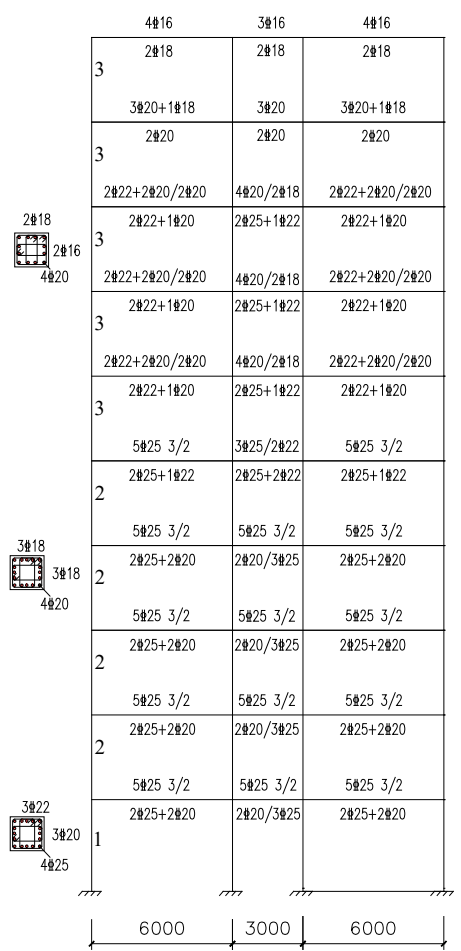

(a) Non-Iso

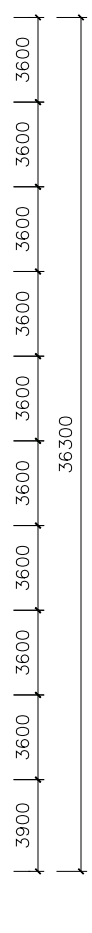

Fig. 2. Structural configuration

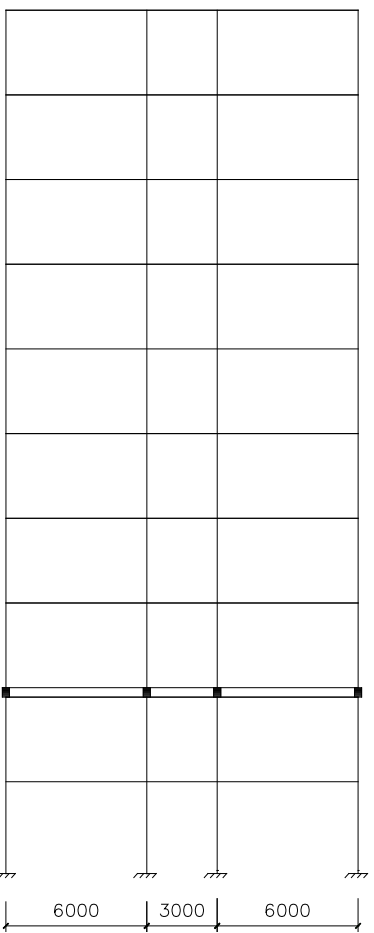

(b) Iso-2

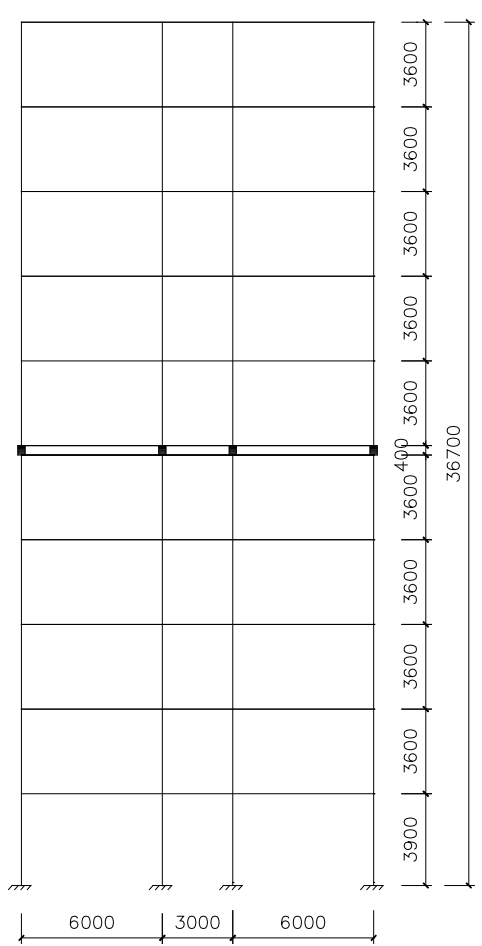

(c) Iso-5

Structural dynamic analysis for both non-isolated and mid-story isolation structures is conducted with OpenSees software. Beams, columns, and isolation bearings are modeled as Beam with Hinges, forceBeamColumn, and zeroLength elements. The fundamental periods of the Non-Iso, Iso-2, and Iso-5 are 1.64s, $2.56 \mathrm{~s}$, and $2.38 \mathrm{~s}$ respectively. It should be noted the dynamic characteristics results of mid-story isolation structures are deduced corresponding to the equivalent stiffness (100\% shear deformation) of bearings.

\section{Result and discussion}

Incremental dynamic analyses are performed to evaluate the seismic performance of reinforced concrete frames subjected to far-field and near-field earthquakes. In this study, the PGA level is adopted as the intensity measure for earthquake and the scale factors for PGA vary from $0.05 \mathrm{~g}$ to $1.0 \mathrm{~g}$.

The maximum inter-story drifts obtained for the Iso-2 and Iso-5 under far-field and near-field ground motions are plotted in Figs. 3-4 respectively. Each data point represents the response of nonlinear dynamic time-history analysis. DS1, DS2, DS3, and DS4 respectively represent slight, moderate, extensive, and collapse damage state. Moreover, the maximum inter-story drifts contained that of both superstructure and substructure. It can be observed from Figs. 3-4 that, the seismic responses with different locations of the isolation layer under near-field records are significantly larger than that subjected to the far-field records. It indicates that the impulse effect of the near-field earthquake enlarged the structural responses. Furthermore, with the increase of the location layer, there is a noticeable increase in maximum inter-story drifts. 


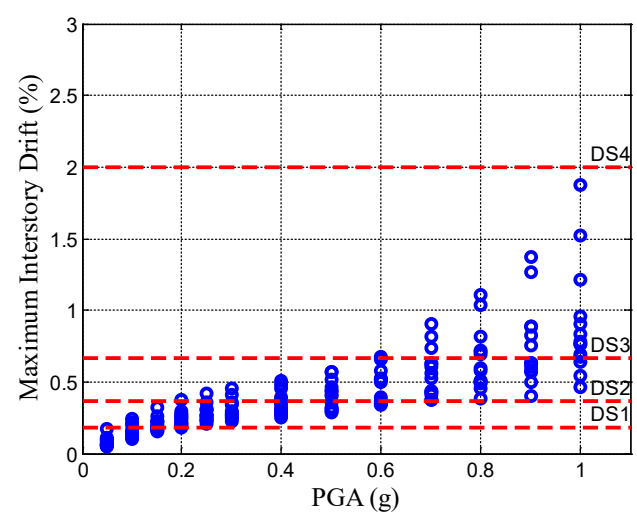

(a) Far-field records set

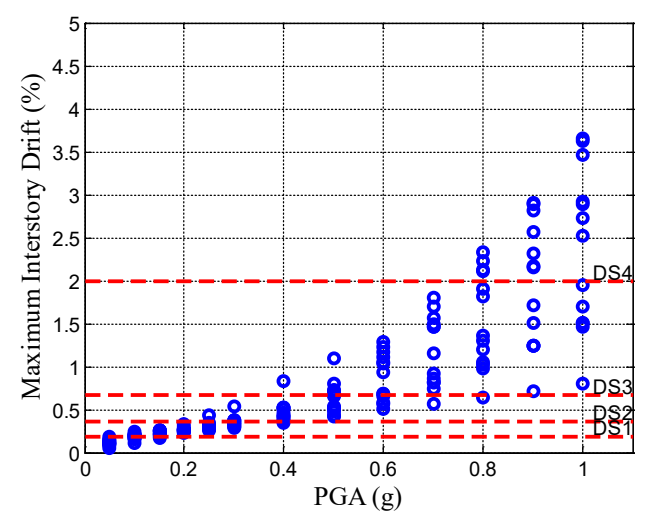

(b) Near-field records set

Fig. 3. Distribution of maximum inter-story drift (Iso-2)

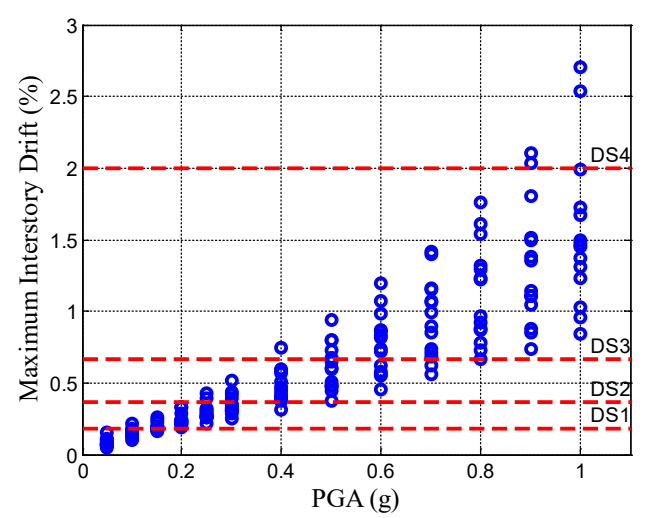

(a) Far-field records set

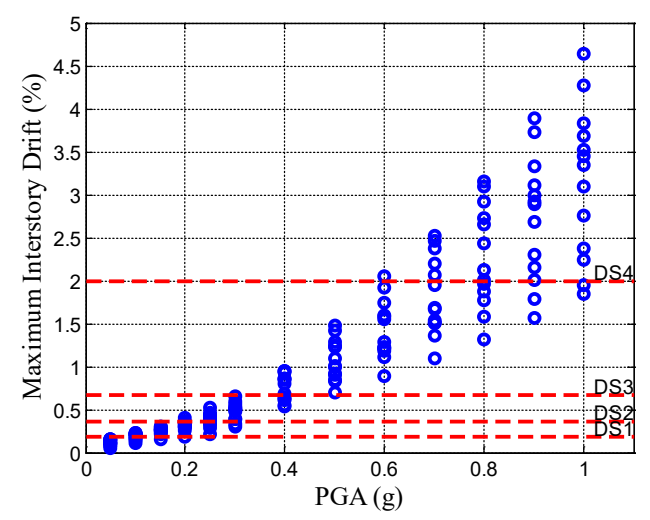

(b) Near-field records set

Fig. 4. Distribution of maximum inter-story drift (Iso-5)

The probability density function can be obtained from the statistics of the response data, and then the integration is performed to obtain the damage probability corresponding to each damage state, thereby the seismic fragility curves at four performance levels defined in Table 1 can be depicted. It is found that the stress bearings vary within the allowable range, and hence are not discussed here.

Comparisons of fragility curves between Non-Iso and Iso-2 are shown in Fig. 5, where Non-Iso, Iso-Sub, Iso-Sup, and Iso-LRB represent the non-isolated structure, substructure, superstructure, and isolation layer of the mid-isolated structures, while $\mathrm{N}$ and $\mathrm{F}$ represent near-field and far-field ground motions respectively. It can be seen that as the structural damage state changes from the slight to the collapsed state, the structural vulnerability curve becomes flat and the probability of damage becomes smaller, which conforms to the structural principle. Regardless of the damage state, the damage probability subjected to the near-field ground motions is much greater than that under the far-field ground motions. The damage probability of Iso-2 decreases significantly compared to Non-Iso, which indicates the efficiency of the mid-story isolation technology. It is important to note that the damage probability of Iso-LRB and Iso-Sup is larger than Iso-Sub in the case of extensive and collapse damage states, as depicted in Figs. 5(c)-(d). Thus, the failure of the structure is mainly caused by the failure of the superstructure and the isolation layer. 

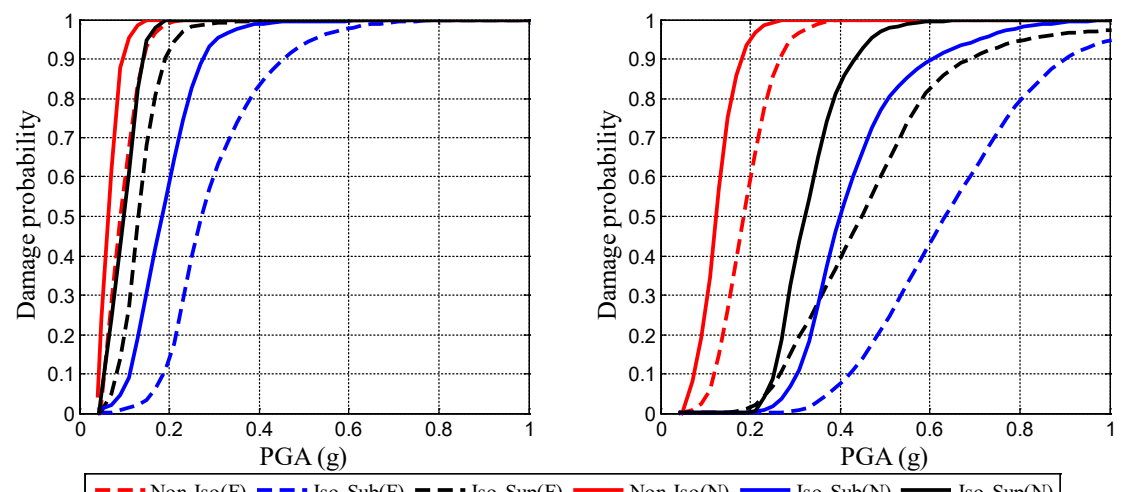

(a) Slight

(b) Moderate
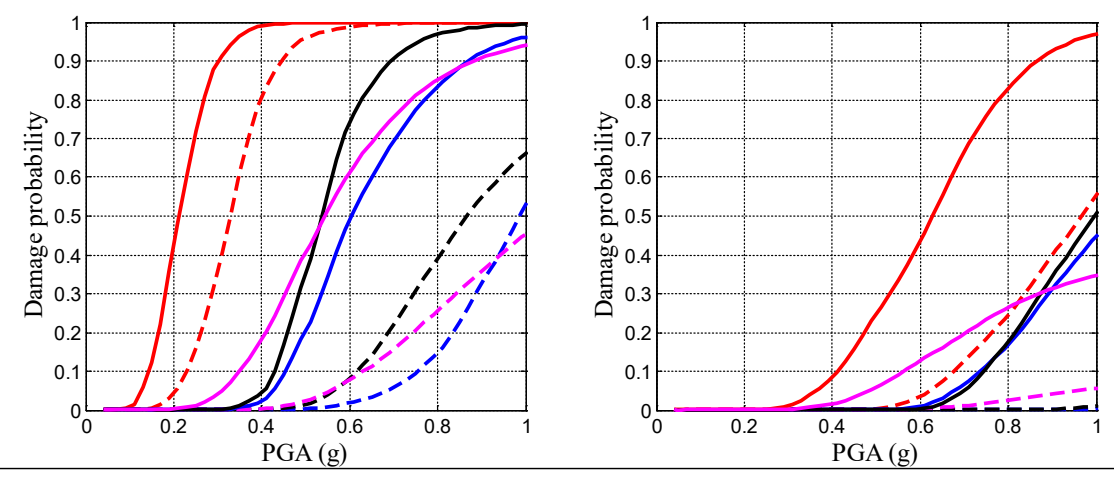

- - - Non-Iso(F) - - - Iso-Sub(F) - - - Iso-Sup(F) - - - Iso-LRB(F)

(c) Extensive

(d) Collapse

Fig. 5. Comparation of fragility curves between Non-Iso and Iso-2

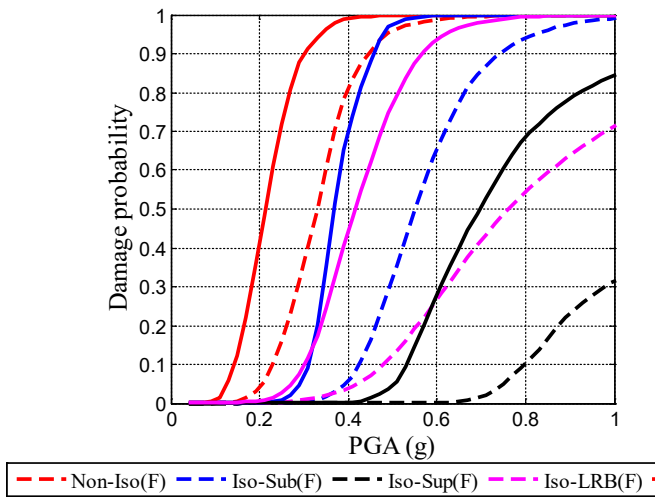

(a) Extensive

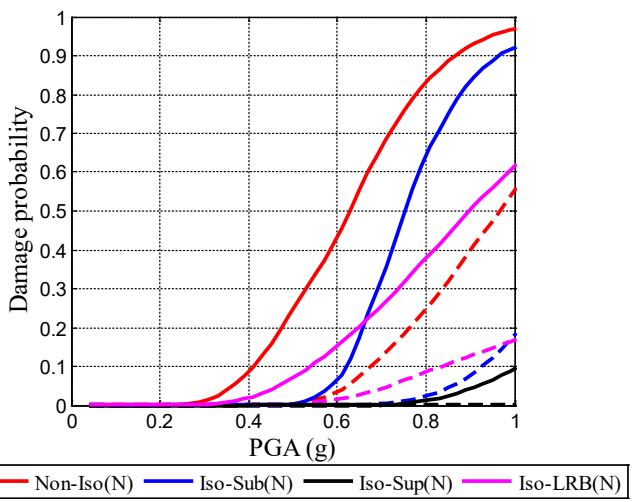

(b) Collapse

Fig. 6. Comparation of fragility curves between Non-Iso and Iso-5

To investigate the influence of the location of the isolation layer on the performance of mid-story isolation structures, fragility curves for the extensive and collapse damage levels are summarized in Fig. 6. Comparing the results with Fig. 5, it can be seen that the trend of Iso-2 and Iso-5 in the damage probability for different sets of ground motions is almost the same, while the distribution of the damage probability of different parts of the structure are changed when the isolation layer varies from 2 nd story to 5th story. In addition, it is obvious that the damage 
probability of Iso-LRB and Iso-Sub is larger than Iso-Sup in the case of extensive and collapse states, which indicates that the collapse of Iso-5 is mainly governed by the failure of the isolation layer and substructure.

\section{Conclusion}

In this study, the results obtained from the fragility analysis of two mid-story isolation structures and non-isolated structure, lead to the following conclusion:

1. By installing the isolation layer into the structures, the seismic responses of both superstructure and substructure are effectively reduced, and the damage probabilities of the mid-story isolation structures are significantly reduced comparing to the corresponding non-isolated structure. The same trend can be observed when subjected to different sets of ground motions.

2. The responses and the damage probability of the mid-isolation structures subjected to the near-field earthquakes are much greater than those subjected to the far-field earthquakes.

3. For the structure with a high location of the isolation layer, the mid-story isolated structure still has the desired isolating effect. However, the damage probability of mid-story isolated structures is correlated with the location of the isolation system. With the increase of the location of the isolation layer, the dominant parts for the failure of mid-story isolated structures change from superstructure and isolation system to substructure and isolation system.

\section{References}

[1] Tsuneki Y, Torii S, Murakami K, et al, Middle-story isolated structural system of high-rise building, The 14th World Conference on Earthquake Engineering, Beijing, China, 2008.

[2] Nakamizo D, Koitabashi Y, Structural Design of Mid-Story Isolated High-Rise Building-Roppongi Grand Tower, International Journal of High-Rise Buildings, 2018, 7(3): pp.233-242.

[3] Kircil M S, Polat Z. Fragility analysis of mid-rise R/C frame buildings. Engineering Structures, 2006, 28(9), pp.1335-1345. https://doi.org/10.1016/j.engstruct.2006.01.004

[4] Bakalis K, Vamvatsikos D. Seismic Fragility Functions via Nonlinear Response History Analysis. Journal of structural engineering, 2018, 144(10):04018181.1-04018181.15. https://doi.org/10.1061/(ASCE)ST.1943-541X.0002141

[5] Vamvatsikos D, Cornell C A. Incremental dynamic analysis. 2002, 31(3), pp.491-514. https://doi.org/10.1002/eqe.141

[6] Mansouri I, Ghodrati Amiri G, Hu J W, et al. Seismic fragility estimates of LRB base isolated frames using performance-based design. Shock and Vibration, 2017.

https://doi.org/10.1155/2017/5184790

[7] Bhandari M, Bharti S D, Shrimali M K, et al. Seismic fragility analysis of base-isolated building frames excited by near-and far-field earthquakes. Journal of Performance of Constructed Facilities, 2019, 33(3): 04019029. https://doi.org/10.1061/(ASCE)CF.1943-5509.0001298

[8] Shome N. Probabilistic seismic demand analysis of nonlinear structures, 1999.

[9] Miranda E, Aslani H. Probabilistic response assessment for building-specific loss estimation. Pacific Earthquake Engineering Research Center, 2003.

[10] Applied Technology Council. Quantification of building seismic performance factors. US Department of Homeland Security, FEMA, 2009. 